\title{
An improved algorithm for polar cloud-base detection by ceilometer over the ice sheets
}

\author{
K. Van Tricht ${ }^{1}$, I. V. Gorodetskaya ${ }^{1}$, S. Lhermitte ${ }^{1,2}$, D. D. Turner ${ }^{3}$, J. H. Schween ${ }^{4}$, and N. P. M. Van Lipzig ${ }^{1}$ \\ ${ }^{1}$ KU Leuven, Department of Earth and Environmental Sciences, Leuven, Belgium \\ ${ }^{2}$ Royal Netherlands Meteorological Institute (KNMI), De Bilt, the Netherlands \\ ${ }^{3}$ NOAA National Severe Storms Laboratory, Norman, Oklahoma, USA \\ ${ }^{4}$ Institute for Geophysics and Meteorology, University of Cologne, Cologne, Germany
}

Correspondence to: K. Van Tricht (kristof.vantricht@ees.kuleuven.be)

Received: 8 October 2013 - Published in Atmos. Meas. Tech. Discuss.: 14 November 2013

Revised: 1 March 2014 - Accepted: 17 March 2014 - Published: 6 May 2014

\begin{abstract}
Optically thin ice and mixed-phase clouds play an important role in polar regions due to their effect on cloud radiative impact and precipitation. Cloud-base heights can be detected by ceilometers, low-power backscatter lidars that run continuously and therefore have the potential to provide basic cloud statistics including cloud frequency, base height and vertical structure. The standard cloud-base detection algorithms of ceilometers are designed to detect optically thick liquid-containing clouds, while the detection of thin ice clouds requires an alternative approach. This paper presents the polar threshold (PT) algorithm that was developed to be sensitive to optically thin hydrometeor layers (minimum optical depth $\tau \geq 0.01$ ). The PT algorithm detects the first hydrometeor layer in a vertical attenuated backscatter profile exceeding a predefined threshold in combination with noise reduction and averaging procedures. The optimal backscatter threshold of $3 \times 10^{-4} \mathrm{~km}^{-1} \mathrm{sr}^{-1}$ for cloud-base detection near the surface was derived based on a sensitivity analysis using data from Princess Elisabeth, Antarctica and Summit, Greenland. At higher altitudes where the average noise level is higher than the backscatter threshold, the PT algorithm becomes signal-to-noise ratio driven. The algorithm defines cloudy conditions as any atmospheric profile containing a hydrometeor layer at least $90 \mathrm{~m}$ thick. A comparison with relative humidity measurements from radiosondes at Summit illustrates the algorithm's ability to significantly discriminate between clear-sky and cloudy conditions. Analysis of the cloud statistics derived from the PT algorithm indicates a year-round monthly mean cloud cover fraction of $72 \%( \pm 10 \%)$ at Summit without a seasonal cycle. The
\end{abstract}

occurrence of optically thick layers, indicating the presence of supercooled liquid water droplets, shows a seasonal cycle at Summit with a monthly mean summer peak of $40 \%$ $( \pm 4 \%)$. The monthly mean cloud occurrence frequency in summer at Princess Elisabeth is $46 \%( \pm 5 \%)$, which reduces to $12 \%( \pm 2.5 \%)$ for supercooled liquid cloud layers. Our analyses furthermore illustrate the importance of optically thin hydrometeor layers located near the surface for both sites, with $87 \%$ of all detections below $500 \mathrm{~m}$ for Summit and $80 \%$ below $2 \mathrm{~km}$ for Princess Elisabeth. These results have implications for using satellite-based remotely sensed cloud observations, like CloudSat that may be insensitive for hydrometeors near the surface. The decrease of sensitivity with height, which is an inherent limitation of the ceilometer, does not have a significant impact on our results. This study highlights the potential of the PT algorithm to extract information in polar regions from various hydrometeor layers using measurements by the robust and relatively low-cost ceilometer instrument.

\section{Introduction}

Clouds have an important effect on the polar climates. Locally, polar tropospheric clouds influence the energy and mass balance of the ice sheets (Bintanja and Van den Broeke, 1996; Intrieri, 2002; Bromwich et al., 2012; Kay and L'Ecuyer, 2013). The changes in cloud properties may modify the climate of regions at lower latitudes as well (Lubin et al., 1998). Climate models still have difficulties in 
correctly projecting the polar climate, which is among others due to uncertainties in cloud parameterisations of macro- and microphysical properties (Bennartz et al., 2013; Ettema et al., 2010; Gorodetskaya et al., 2008) and feedback mechanisms (Dufresne and Bony, 2008).

Despite the great importance of clouds on the surface mass and energy balance, cloud research at high latitudes is still hampered by a lack of sufficient cloud observations. The harsh and remote environment of the Arctic and Antarctic has limited the amount of ground stations used for climatic research. The research sites that are present are equipped with robust instruments that can withstand very cold conditions. One of the most robust instruments that is used for observing clouds is the ceilometer, a ground-based low-power lidar device. It can operate continuously in all weather conditions (Hogan et al., 2003) and is one of the more abundant (>10) instruments at Arctic and Antarctic stations, including at Summit, Atqasuk, Barrow, Ny-Ålesund (Arctic study sites) and at Princess Elisabeth, Rothera, Halley (Antarctic study sites) (Bromwich et al., 2012; Shanklin et al., 2009; Shupe et al., 2011).

A macrophysical property inferred from ceilometer data is the cloud-base height $(\mathrm{CBH})$ which is defined as the lower boundary of a cloud. The CBH is used for different purposes, including visibility determination, cloud height occurrence statistics and validation of other remotely sensed cloud measurements, such as satellite observations. Most often, the $\mathrm{CBH}$ is calculated by built-in algorithms developed by the instrument's manufacturers such as the Vaisala cloud-base detection algorithm (Garrett and Zhao, 2013; Shupe et al., 2011). These built-in algorithms are primarily designed to report the altitude where the horizontal visibility is drastically reduced from a pilot point of view (Flynn, 2004), which typically occurs in liquid clouds. These algorithms are therefore not suited to detect base heights of optically thin ice clouds that frequently occur over the ice sheets. Bernhard (2004) showed that at the South Pole $71 \%$ of all clouds have an optical depth below 1 and the Arctic clouds are also frequently optically thin (Sedlar et al., 2010; Shupe and Intrieri, 2004). Despite the low-optical depth of ice clouds, their detection is important in terms of determination of the cloud radiative impact or potential precipitation growth (Sun and Shine, 1995; Curry et al., 1996; Pruppacher and Klett, 2010; Kay and L'Ecuyer, 2013).

Ceilometers typically detect cloud bases in regions with high backscatter (see e.g. Fig. 1) that are likely related to liquid-containing portions in case of a mixed-phase cloud (Bromwich et al., 2012; Curry et al., 2000; Hobbs and Rangno, 1998; Pinto, 1998; Uttal et al., 2002; Verlinde et al., 2007). Yet, there are clearly regions with increased backscatter below. The optically much thicker top layer most probably related to supercooled liquid has a much higher backscatter coefficient compared to the optically thin layer below. The conventional algorithms report this liquid cloud base, while detection of the ice cloud base below is also of great

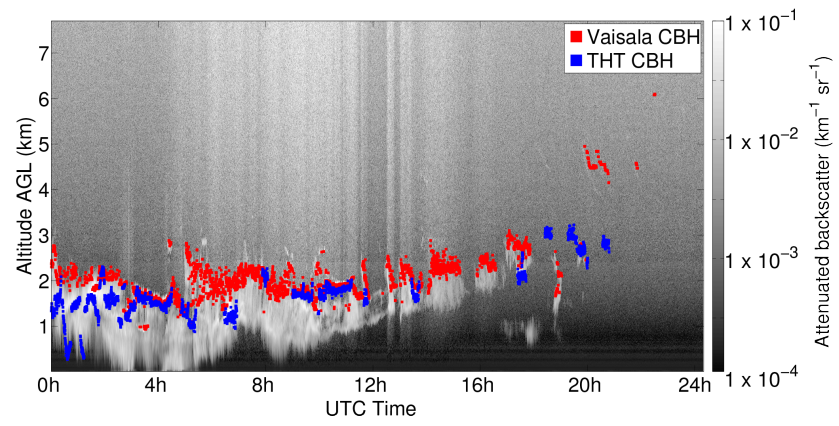

Fig. 1. Ceilometer attenuated backscatter image at Princess Elisabeth (14 March 2011) on a logarithmic scale. Red dots represent the $\mathrm{CBH}$ calculated by the built-in Vaisala algorithm. Blue dots represent the $\mathrm{CBH}$ calculated by the THT algorithm.

importance. There are also other $\mathrm{CBH}$ detection algorithms that use different approaches to infer $\mathrm{CBH}$, for instance, the temporal height tracking (THT) algorithm developed by Martucci et al. (2010) that uses backscatter maxima and backscatter gradient maxima to calculate the $\mathrm{CBH}$. Performance of the THT algorithm was shown to be superior for detecting warm liquid clouds, particularly when these clouds were rapidly changing in time. However, this algorithm has not been designed to detect optically thin clouds in a polar atmosphere, which is apparent from the $\mathrm{CBH}$ detections by the THT algorithm in Fig. 1. Other more advanced instruments are also reporting $\mathrm{CBH}$, such as the micropulse lidar (MPL) (e.g., Clothiaux et al., 1998; Campbell et al., 2002), but these instruments are less abundant over the different study sites in the Arctic and Antarctic, mostly due to their complexity, higher cost and the need for a manned station to operate such systems on site (Barnes et al., 2003). An algorithm that is capable of calculating the $\mathrm{CBH}$ from ceilometer data in polar regions, including the detection of very optically thin ice layers, therefore would greatly improve cloud statistics in these areas.

The goal of this study is to develop a simple method that uses ceilometer measurements to detect optically thin ice clouds and liquid-containing clouds as well as any form of precipitation, all of which are important for the radiative budget and mass balance of the ice sheets (Bintanja and Van den Broeke, 1996; Bromwich et al., 2012; Curry et al., 1996; Intrieri, 2002; Pruppacher and Klett, 2010; Sun and Shine, 1995). We propose to use a fairly straightforward backscatter threshold approach. We describe here the theoretical framework of the new algorithm, the determination of the optimal backscatter threshold and results that were obtained by applying the algorithm on the ceilometer measurements at an Arctic and an Antarctic station. 


\section{Data}

\subsection{Study area}

The locations of the two research stations used in this study are shown in Fig. 2. They were chosen based on their characteristic climatology and available instrumentation.

The Antarctic data originate from the Princess Elisabeth (PE) station (Pattyn et al., 2009), located in the escarpment zone of Dronning Maud Land, East-Antarctica. The station is situated on the Utsteinen Ridge near the Sør Rondane mountains at an elevation of 1382 ma.s.l., $220 \mathrm{~km}$ inland $\left(71.95^{\circ} \mathrm{S}, 23.35^{\circ} \mathrm{E}\right)$. Its location makes the station well protected from katabatic winds; however, with a significant influence of coastal storms $50 \%$ of the time (Gorodetskaya et al., 2013). Cloud measurements are carried out in the context of the HYDRANT project (the atmospheric branch of the HYDRological cycle in ANTarctica), for which a unique instrument set has been installed, including a ceilometer, an uplooking infrared radiation pyrometer, a vertically pointing micro rain radar and an automatic weather station (Gorodetskaya et al., 2014). Data are currently limited to summertime cases due to power outages in wintertime. Cases used in this study are selected from December to March between 2010 and 2013.

The Arctic cloud data were recorded at the Summit station atop the Greenland Ice Sheet, $3250 \mathrm{ma} . \mathrm{s} .1$. $\left(72.6^{\circ} \mathrm{N}\right.$, $\left.38.5^{\circ} \mathrm{W}\right)$. The station is located $400 \mathrm{~km}$ inland from the nearest coastline, making it a continental study site. The atmosphere on top of the ice sheet is extremely dry and cold, while many cloud properties are comparable to other Arctic regions (Shupe et al., 2013). The station is equipped with an extensive instrument set, including both passive as well as active sensors and a twice-daily radiosonde program, making this research site unique for cloud observing purposes. The cases used in this study are year-round measurements between 2010 and 2012 as part of the Integrated Characterization of Energy, Clouds, Atmospheric state, and Precipitation at Summit (ICECAPS) project (Shupe et al., 2013).

\subsection{Ceilometer}

The Greenland Summit station is equipped with a Vaisala CT25K laser ceilometer, while the Antarctic PE station has the newer Vaisala CL31 laser ceilometer. Both instruments are emitting low-energy laser pulses and their vertical range extends up to $7.5 \mathrm{~km}$. The CL31 instrument is more sensitive than the CT25K due to a higher average emitted power. Further technical details of both ceilometers are given in Table 1.

The output used in this study is the range and sensitivity corrected attenuated backscatter coefficient $\beta_{\mathrm{att}}\left(\mathrm{km}^{-1} \mathrm{sr}^{-1}\right)$, which describes how much light from the emitted laser pulse is scattered into the backward direction, not corrected for attenuation by extinction. It is the product of the volume backscatter coefficient $\beta$ at a certain height range and

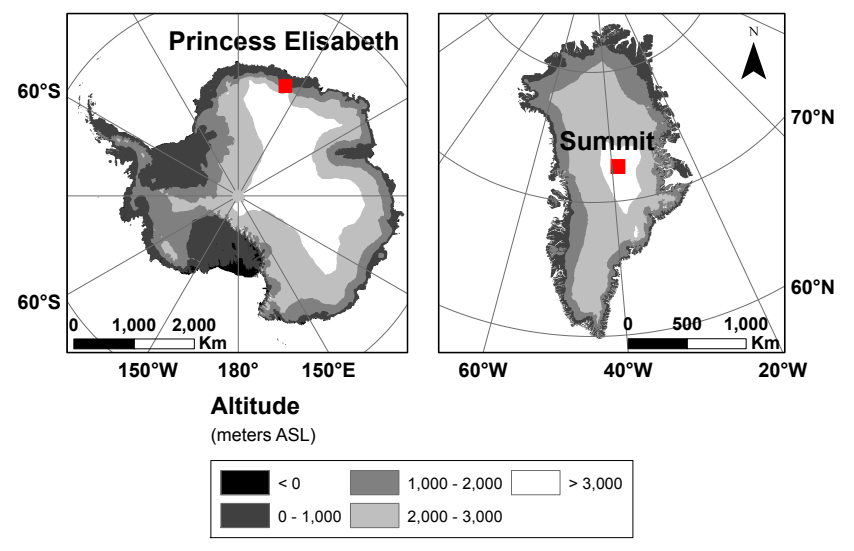

Fig. 2. Locations of PE (Antarctica) and Summit (Greenland) research stations.

the two-way attenuation of the atmosphere between the ceilometer and the scattering volume (Münkel et al., 2006). It is found after multiplying the received power by all instrument specific factors (including a generic overlap correction), constants and the squared distance. Since the transmittance of the atmosphere is in general unknown, conversion of the attenuated backscatter coefficient $\beta_{\text {att }}$ to the true volume backscatter coefficient $\beta$ is not straightforward. The returned signal of the pulses is averaged over a period of $15 \mathrm{~s}$ which determines the temporal resolution of the measurements. The vertical resolution is $30 \mathrm{~m}$ for the CT25K at Summit and $10 \mathrm{~m}$ for the CL31 at PE.

An additional difference between both ceilometers is the precision of the reported backscatter. The CT25K reports integer values of attenuated backscatter in $1 \times 10^{-4} \mathrm{~km}^{-1} \mathrm{sr}^{-1}$, while the CL31 reports in $1 \times 10^{-5} \mathrm{~km}^{-1} \mathrm{sr}^{-1}$ (i.e. a factor 10 more precise). Calibration of the raw CT25K data was necessary, which was done based on the autocalibration method by O'Connor et al. (2004). They showed that supercooled water layers have essentially the same characteristics as warm stratocumulus clouds for which the method was developed. We therefore selected cases with supercooled water layers that completely attenuate the laser beam without saturating the detectors, for which the lidar ratio is assumed to be constant and known (see Sect. 4.3). We filtered these cases to retain profiles with a minimum amount of ice precipitation, since ice precipitation violates the constant lidar ratio assumption. Due to the low beam divergence and small field of view of the CT25K ceilometer (Table 1 ), the effect of multiple scattering is small. Applying the autocalibration method resulted in a scale factor of 3 . The inevitable presence of ice in certain profiles invalidates some of the assumptions in the O'Connor method and introduces an additional uncertainty in the calibrated data. Despite this, the autocalibration method significantly improved the large biases that were encountered in the raw CT25K measurements. After calibration of the Summit ceilometer, the minimum reported attenuated backscatter 
Table 1. Technical specifications of CT25K (Summit) and CL31 (PE) ceilometers.

\begin{tabular}{|c|c|c|}
\hline Parameter & $\mathrm{CT} 25 \mathrm{~K}$ & CL31 \\
\hline Wavelength & $905 \mathrm{~nm}$ & $910 \mathrm{~nm}$ \\
\hline Energy per pulse & $1.6 \pm 20 \% \mu \mathrm{J}$ & $1.2 \pm 20 \% \mu \mathrm{J}$ \\
\hline Pulse repetition rate & $5.57 \mathrm{kHz}$ & $10 \mathrm{kHz}$ \\
\hline Average emitted power & $8.9 \mathrm{~mW}$ & $12 \mathrm{~mW}$ \\
\hline Time resolution & $15 \mathrm{~s}$ & $15 \mathrm{~s}$ \\
\hline Range & $7.5 \mathrm{~km}$ & $7.7 \mathrm{~km}$ \\
\hline Range resolution & $30 \mathrm{~m}$ & $10 \mathrm{~m}$ \\
\hline Backscatter units (precision) & $1 \times 10^{-4} \mathrm{~km}^{-1} \mathrm{sr}^{-1}$ & $1 \times 10^{-5} \mathrm{~km}^{-1} \mathrm{sr}^{-1}$ \\
\hline Min. detection limit & $3 \times 10^{-4} \mathrm{~km}^{-1} \mathrm{sr}^{-1}$ & $1 \times 10^{-5} \mathrm{~km}^{-1} \mathrm{sr}^{-1}$ \\
\hline Beam divergence & $\pm 0.53 \mathrm{mrad}$ edge, $\pm 0.75 \mathrm{mrad}$ diagonal & $\pm 0.4 \mathrm{mrad}$ edge, $\pm 0.7 \mathrm{mrad}$ diagonal \\
\hline Field-of-view divergence & $\pm 0.66 \mathrm{mrad}$ & $\pm 0.83 \mathrm{mrad}$ \\
\hline
\end{tabular}

value is $3 \times 10^{-4} \mathrm{~km}^{-1} \mathrm{sr}^{-1}$, while $1 \times 10^{-5} \mathrm{~km}^{-1} \mathrm{sr}^{-1}$ is the minimum value reported by the $\mathrm{PE}$ ceilometer.

\subsection{Radiosondes}

Among the observations at Summit, twice a day a radiosonde program for characterising the atmospheric state is run (Shupe et al., 2013). Relative humidity (RH) is measured with the Vaisala RS92-K and RS92-SGP sondes and reported at a temporal resolution of $2 \mathrm{~s}$, resulting in a vertical $\mathrm{RH}$ profile. Due to the low atmospheric temperatures, we report the $\mathrm{RH}$ with respect to ice $\left(\mathrm{RH}_{\mathrm{ice}}\right)$, using Tetens formulation as described by Murray (1967). This formulation requires an extreme accuracy at low temperatures. The high uncertainty of the RH measurements at cold temperatures (dry bias) for the RS80 and RS90 sondes (Miloshevich et al., 2001; Rowe et al., 2008; Wang et al., 2013), is mostly resolved with the RS92 sondes (Suortti et al., 2008). Additionally, quantitative studies show that this issue is less severe in polar regions (Vömel et al., 2007), because the solar elevation angle is lower at high latitudes. Suortti et al. (2008) moreover identified the RS92 sonde as being superior to other radiosonde sensors.

\section{Polar threshold algorithm}

The development of a $\mathrm{CBH}$ detection algorithm depends on atmospheric features considered to be a cloud. In this study a cloud is defined to be any hydrometeor layer at least $90 \mathrm{~m}$ thick in the atmospheric column detected by the ceilometer. Our new $\mathrm{CBH}$ detection algorithm determines the height of the first detectable occurrence of hydrometeors in a layer defined this way. We do not attempt to distinguish between clouds and precipitation, since our broad definition of a cloud and its importance for the energy and mass budget includes precipitation as well. This is different from the conventional algorithms that try to identify the base of the cloud above the precipitation layer given that the latter does not entirely attenuate the signal.

Since our aim was to detect the $\mathrm{CBH}$ in optically thin layers, even if liquid water droplets are present above them, the developed polar threshold (PT) algorithm compares the measured attenuated backscatter to a predefined backscatter threshold. This allows the algorithm to be sensitive to optically thin hydrometeor layers characterized by low attenuated backscatter returns and a lack of sharp gradients. This is an essential way by which our approach differs from both the standard Vaisala algorithm (Flynn, 2004) and the THT algorithm (Martucci et al., 2010) that look at visibility or backscatter (gradient) maxima. In this section we first describe the noise reducing and averaging procedures to be carried out prior to the actual $\mathrm{CBH}$ detection, followed by the principles of the threshold approach and the procedure to determine the optimal backscatter threshold.

\subsection{Noise reduction and averaging}

For a sensitive algorithm to work properly, noise levels should be reduced and useful signal should be emphasized. The ceilometer being a low-power lidar inherently reports attenuated backscatter with a considerable degree of noise (e.g., Clothiaux et al., 1998). The fast decrease of signal with range and its range correction (evident from the lidar equation in e.g. Münkel et al., 2006) leads to increasing noise levels higher in the profile. We therefore first remove noisy data detected by investigating the signal-to-noise ratio (SNR) and afterwards average the raw ceilometer attenuated backscatter data. The SNR was calculated for every separate height range bin at time step $i$ and range bin $j$ as

$$
\mathrm{SNR}_{i, j}=\frac{\bar{\beta}_{i, j}}{\sqrt{\frac{1}{2 M} \sum_{k=-M}^{+M}\left(\beta_{i+k, j}-\bar{\beta}_{i, j}\right)^{2}}}
$$




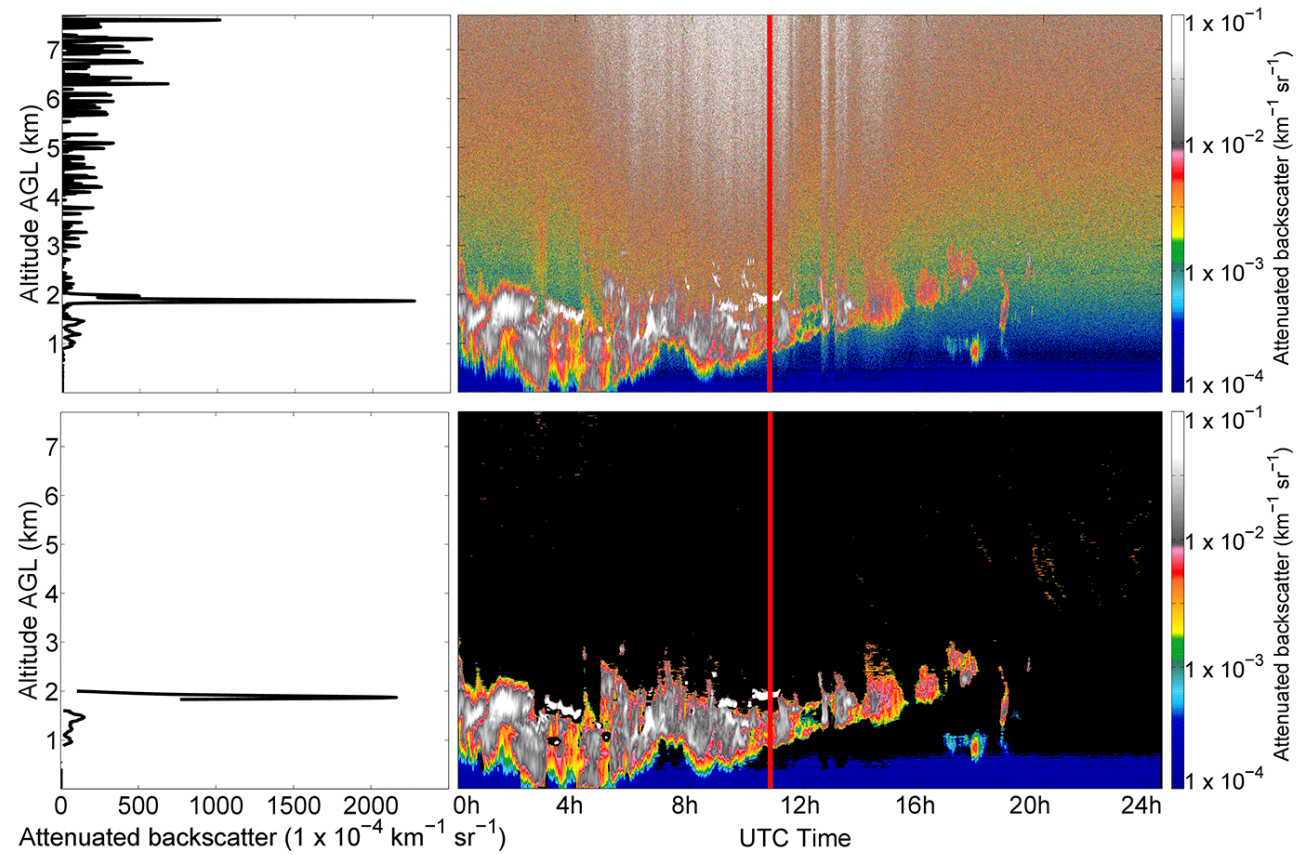

Fig. 3. Ceilometer attenuated backscatter $\left(\mathrm{km}^{-1} \mathrm{sr}^{-1}\right)$ at PE (14 March 2011) with example profile, indicated by the red line, before (top) and after (bottom) noise reduction and averaging procedures. Negative noise values are not shown in the left figures. Range bins where the $\mathrm{SNR}<1$ are not shown in the lower left image and are plotted in black in the lower right image.

which is the ratio of the temporal mean $\bar{\beta}_{i, j}$ and standard deviation of the attenuated backscatter over $\pm M$ time steps around time step $i$ and range bin $j$.

Provided that the temporal resolution of the individual profiles is $15 \mathrm{~s}, M$ is equal to 20 profiles for a time interval of $10 \mathrm{~min}$. The atmospheric fluctuations in this interval are small compared to the instrument noise such that the standard deviation over the interval mainly contains internal noise from the instrument. This method is different from the common techniques used for lidars to estimate the ceilometer's noise level from the background light (see e.g. Heese et al., 2010; Stachlewska et al., 2012; Wiegner and Geiß, 2012). In theory, the background light, reported as voltages by the Vaisala ceilometers, could be used to derive a relationship with noise present in the data. In application to the polar atmosphere, however, this voltage is extremely small due to the low-solar zenith angle and low scattering in clear polar air. Therefore, we propose to work with the method as described in Eq. (1). Noisy data are characterized by a low mean backscatter (averaged over positive and negative values) and a high standard deviation, resulting in low SNR values. The SNR threshold was set to 1 as was also done by Heese et al. (2010), and pixels with a lower SNR were removed. The impact of this choice was assessed as well by varying this SNR threshold between 0.5 and 1.5. For the final analyses, the noise-reduced data were smoothed by applying a running mean over an interval of $2.5 \mathrm{~min}$, determining the final temporal resolution of the data. Due to the impact of the averaging method on the results as reported in Stachlewska et al. (2012), we varied the running mean interval between 1 and $15 \mathrm{~min}$, but the impact on our results was below $1 \%$. Figure 3 shows an example ceilometer attenuated backscatter image with a typical backscatter profile before and after the noise reduction and averaging procedures.

\subsection{Threshold approach}

Following Platt et al. (1994), who used a threshold method to detect cloud bases, the PT algorithm is also using a threshold approach. Platt et al. (1994) used a multiple of the standard deviation of the background fluctuations as a threshold to be exceeded by the attenuated backscatter signal as one of the conditions for cloud-base detection. This approach is similar to the definition of the SNR that is used in this study, with the value of the SNR threshold determining which data points remain for possible cloud-base detection by the PT algorithm. However, as discussed in Sect. 3.1, the background signal of clear polar air is extremely small. As noise levels are lowest near the surface, the standard deviation of this background signal near the surface is accordingly extremely small, which is problematic for using the method by Platt et al. (1994) that is based only on this standard deviation. This is conceptually visualized in Fig. 4, where the black curve indicates the average noise level in a polar ceilometer profile in function of range. Applying the method by Platt et al. (1994) would trigger cloud-base detection near the surface even in clearsky conditions, since the background signal, although very low, will exceed the noise level several times. This is evident 


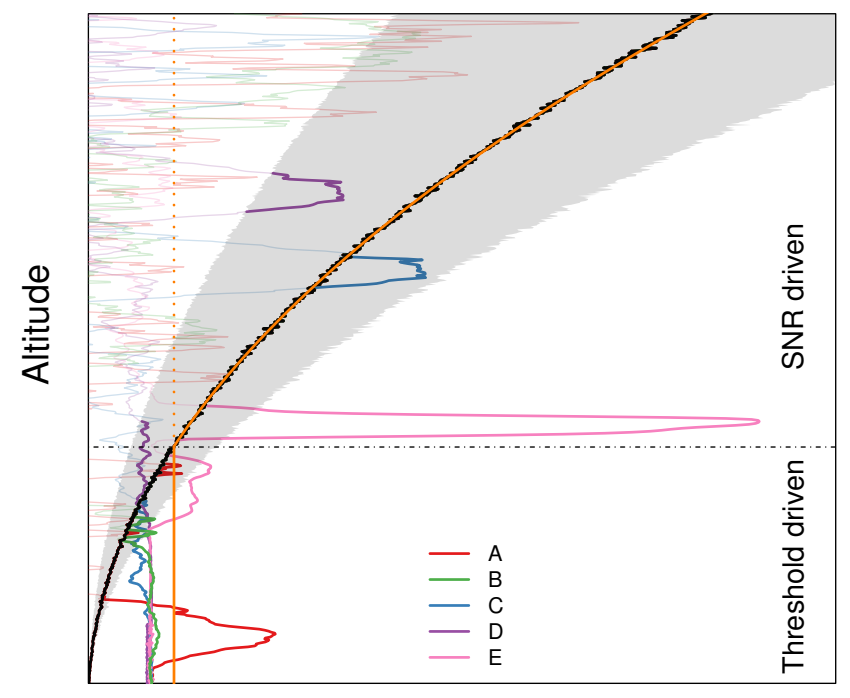

Attenuated backscatter

Fig. 4. Theoretical working of PT algorithm. The black curve indicates the average noise level, increasing with height. The solid orange curve indicates the detection method in function of range as used by the PT algorithm. Five example backscatter profiles are indicated by curves A to E. The horizontal dashed black line shows the altitude above which the detection method becomes SNR driven. The shaded area represents variable detection sensitivity based on the SNR threshold.

in curves B to D in Fig. 4 that do not show cloud occurrence near the surface but would trigger a backscatter threshold that was set to the noise level.

To overcome this issue, we propose a $\mathrm{CBH}$ detection methodology based on an absolute attenuated backscatter threshold near the surface. This allows setting the threshold above the background value. Determination of the optimal threshold as indicated by the straight orange line in Fig. 4 is performed in Sect. 3.3. However, as range increases, the average noise level increases accordingly. At a certain height (indicated by the horizontal dashed black line in Fig. 4), the noise level exceeds the backscatter threshold that was determined near the surface where noise levels are small. Above this height, cloud detection by the ceilometer is limited by the noise present in the data. From this point onwards, cloud detection is therefore limited by the SNR, similar to the approach by Platt et al. (1994), meaning that the PT algorithm then uses a threshold on the SNR for cloud-base detection. Due to the relatively low ceilometer power, noise levels increase with height and some optically thin ice clouds will be missed at high ranges, indicating that the sensitivity of the PT algorithm decreases with height above the point where the detection method becomes SNR driven.

The overall detection method used by the PT algorithm is thus split into two distinctly different parts depending on the height in the profile. This is indicated by the solid orange line in Fig. 4, indicating that the PT algorithm is driven by a fixed attenuated backscatter threshold below the horizontal line where noise levels are very small, and driven by the SNR above the horizontal line, where noise levels become distinctly higher. If the noise reduction is based on a SNR threshold of 1 as determined in Sect. 3.1, this implies in practice that the backscatter of a cloud must be exceeding the noise level persistently in time to be identified as a cloud by the PT algorithm.

The SNR-threshold choice determines the tradeoff between remaining noise in the data (lower SNR threshold) and loss of valid signal (higher SNR threshold) and therefore the sensitivity of the PT algorithm. We therefore evaluated the sensitivity on the results to SNR thresholds between 0.5 and 1.5. The PT algorithm then follows the margins of the shaded area around the noise level in Fig. 4. It is evident that using SNR threshold 0.5 allows the detection of optically thinner clouds (bold purple part in profile D), but introduces false triggering as well (profile B at the higher ranges). Setting the SNR threshold to 1.5 reduces false triggering in noise, but removes some thin clouds as well (bold blue part in profile C). Cloud statistics in Sect. 4.4 are therefore reported together with the sensitivity due the SNR-threshold choice.

The PT algorithm processes every vertical $2.5 \mathrm{~min}$ averaged and SNR-processed profile separately and compares the attenuated backscatter of each range bin to the backscatter threshold in a bottom-up approach. The first $60 \mathrm{~m}$ (2 range bins at Summit, 6 range bins at PE), however, are excluded to minimize the effects of shallow blowing snow layers. The $\mathrm{CBH}$ detection is triggered if the attenuated backscatter at a certain height in the vertical profile exceeds the threshold at that height. After the trigger, the algorithm also considers the mean attenuated backscatter over the minimum cloud thickness distance (set to be $90 \mathrm{~m}$ for both systems) above the trigger point. If the backscatter value over this elevated height also exceeds the threshold, the height of the trigger point is set as the $\mathrm{CBH}$. This ensures a certain amount of robustness of the signal at the detected $\mathrm{CBH}$, meaning that a hydrometeor layer should have a minimum geometrical thickness of $90 \mathrm{~m}$ to be detectable by the algorithm. If not, the algorithm proceeds with the next range bin in the profile. If there is no cloud detection below the point where the average noise level exceeds the backscatter threshold, the PT algorithm looks at range bins that have survived the SNR noise reduction. If the end of the vertical profile is reached without a valid $\mathrm{CBH}$ detection, the profile is marked as clear sky. This approach was found to perform best in identifying the base of optically thin hydrometeor layers. In the event of precipitation to the surface, the sensitive nature of the algorithm will require the $\mathrm{CBH}$ to be placed near the surface above the $60 \mathrm{~m}$ layer frequently contaminated by drifting snow lifted from the surface. Figure 5 shows the ideal result of the PTderived CBH compared to the Vaisala and THT algorithms for an example attenuated backscatter profile. The original (not noise-reduced) ceilometer data are shown. It is evident that the threshold-based PT algorithm can be triggered at 

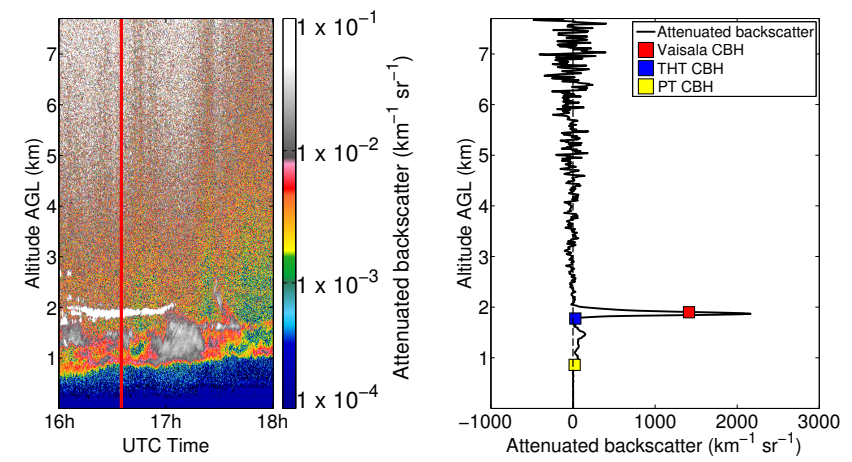

Fig. 5. A time height cross section of the attenuated backscatter coefficient (left) and a comparison between Vaisala (red), THT (blue) and PT (yellow) derived $\mathrm{CBH}$ in an example attenuated backscatter profile (indicated by red line in the left image) at PE on 14 March 2011 (right). Vaisala and THT report the CBH at high backscatter values. The PT algorithm is triggered at low backscatter values.

much lower backscatter values occurring at the base of an optically thin ice layer compared to the other algorithms that are triggered much higher in the profile, most probably at a liquid-containing layer. In the next section, the optimal backscatter threshold to be used by the PT algorithm is determined, in order to achieve results as in Fig. 5.

\subsection{Determining optimal threshold}

The CBH detection by the PT algorithm near the surface strongly depends on the backscatter threshold that is used. As discussed in Sect. 3.2, up to a certain altitude the backscatter threshold should not be based on the noise level to avoid false detections near the surface. The optimal threshold in this region is one that allows the detection of hydrometeor layers with a low optical depth while not triggering the algorithm in clear-sky conditions. To make an appropriate threshold choice, we performed a sensitivity analysis by varying the backscatter threshold between the detection limits of the ceilometers and the maximum backscatter value in the data and evaluating the effect on the cloud detections. The total number of profiles containing a cloud that is detected by the PT algorithm over all cases (i.e. the total number of detections) was calculated for each threshold. The results of the sensitivity analysis for PE are shown in Fig. 6a. At a backscatter threshold just below $3 \times 10^{-4} \mathrm{~km}^{-1} \mathrm{sr}^{-1}$ there is a sharp decrease in total number of detections. At this transition, the total number of detections is approximately halved, which is related to the fact that PE experiences synoptic influence favouring cloud occurrence about $50 \%$ of the time (Gorodetskaya et al., 2013). The backscatter threshold at $3 \times 10^{-4} \mathrm{~km}^{-1} \mathrm{sr}^{-1}$ effectively represents the minimum concentration of hydrometeors detectable by the ceilometer distinguishing cloudy from clear-sky profiles. The choice of the threshold at the sharp decrease in number of detections
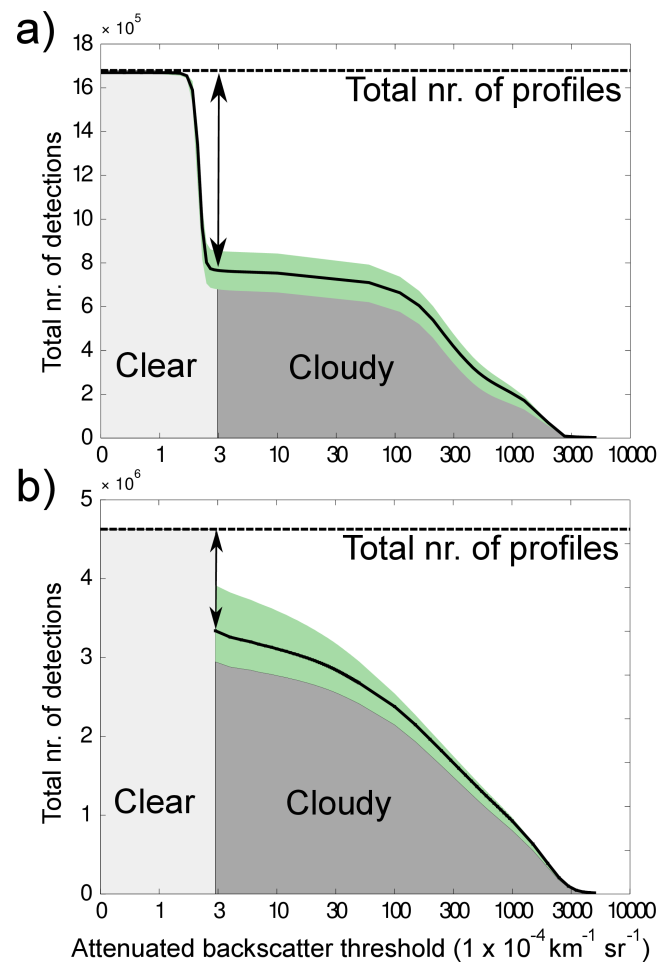

Fig. 6. Sensitivity analyses of backscatter threshold on the cloud detections for (a) PE and (b) Summit. The dashed line indicates the total amount of profiles that have been tested. The arrows show the amount of profiles marked as clear sky using the chosen threshold. The light grey area represents pixels reported as clear by the PT algorithm, while the dark grey area represents pixels reported as cloudy. The green areas represent uncertainty due to SNR-threshold choice.

is possible due to the clear polar troposphere and the negligible ceilometer signal in the absence of clouds. A different relationship is expected for midlatitudes, for example, where the ceilometer signal near the surface will be sensitive to the presence of aerosols. The lowest detection limit after calibration of the ceilometer at Summit corresponds to the backscatter threshold determined for the PE ceilometer (Fig. 6b). Therefore, we used identical backscatter thresholds for PE and Summit. The shaded areas around the black curves indicate that the threshold choice is not very sensitive to the SNR threshold that was used.

The amount of backscatter that reaches the detector is a function of the extinction profile and thus of the optical depth of the atmosphere (Roy et al., 1993). Further increasing the threshold therefore increases the optical depth of the detected clouds and influences both the amount and height of the detected cloudy profiles. Even if the amount of detections does not significantly vary with a changing threshold (flat parts of the curves in Fig. 6), a higher threshold triggers the $\mathrm{CBH}$ detection higher in the backscatter profiles, leading to overall higher $\mathrm{CBH}$ results. For example, increasing the 


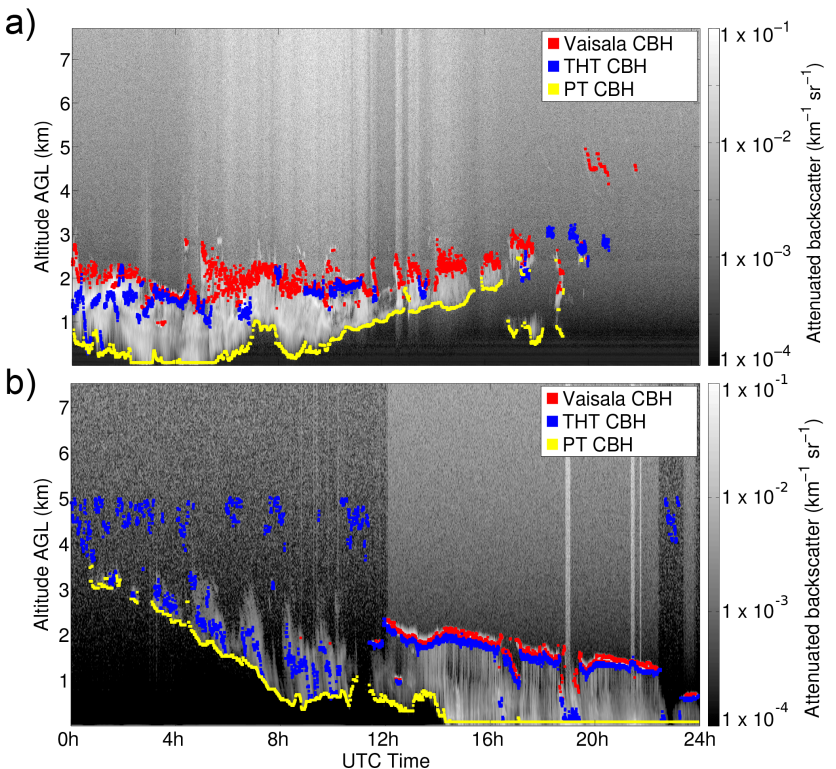

Fig. 7. Comparison of $\mathrm{CBH}$ detection results from Vaisala (red), THT (blue) and PT (yellow) algorithms for (a) PE ceilometer case of 14 March 2011 and (b) Summit ceilometer case of 19 December 2010 .

threshold from $3 \times 10^{-4} \mathrm{~km}^{-1} \mathrm{sr}^{-1}$ to $30 \times 10^{-4} \mathrm{~km}^{-1} \mathrm{sr}^{-1}$ at Summit decreases the amount of detections by $10 \%$ and increases the mean $\mathrm{CBH}$ by $70 \mathrm{~m}$, while at PE the amount of detections is decreased by only $2 \%$, though the mean $\mathrm{CBH}$ increases by $190 \mathrm{~m}$. As our purpose is to detect the optically thinnest detectable hydrometeors lowest in the profile, we choose the lowest backscatter threshold indicating the presence of hydrometeors $\left(3 \times 10^{-4} \mathrm{~km}^{-1} \mathrm{sr}^{-1}\right.$ for both the PE and Summit ceilometers).

\section{Results}

\subsection{Applying the PT algorithm}

The PT algorithm was applied to all available cases at the study sites. Example CBH results for the three tested algorithms are shown in Fig. 7 with the 14 March 2011 case for PE (Antarctic autumn) and the 19 December 2010 case for Summit (Arctic winter). These cases were chosen because they represent different atmospheric conditions on which the PT algorithm could be tested. These conditions include clearsky profiles, ice layers and polar mixed-phase cloud structures (optically thicker layer most probably due to the presence of supercooled liquid over an optically thinner but geometrically thicker ice-only layer). The Summit ceilometer data in Fig. $7 \mathrm{~b}$ indicate that precipitation reaches the surface after $14 \mathrm{~h}$. Since the first 2 range bins of the profile were excluded, the $\mathrm{CBH}$ is located at $60 \mathrm{~m}$ in such conditions.

In both cases, the mean PT CBH is significantly lower compared to the Vaisala and THT CBH. At both study sites, the Vaisala CBH is mostly situated much higher in the cloud, where backscatter values are peaking. This is to be expected since the primary goal of the Vaisala algorithm is to detect visibility changes for pilots. In the case of optically thin features with only low backscatter values, Vaisala sometimes reports the profile as being clear sky (e.g. Fig. 7b from 00:0012:00 UTC). THT takes into account the first derivative of the backscatter profile, while optically thin ice clouds are not characterized by a sharp increase in backscatter. The THT $\mathrm{CBH}$ therefore is often placed higher as well. The PT algorithm is more sensitive and is triggered by optically thinner hydrometeor layers. The number of cloudy profiles reported by PT therefore is higher and the detected $\mathrm{CBH}$ is reported at lower altitudes. The sensitive nature of the PT algorithm indicates that the noise reduction and averaging procedures have to be an inherent part of the algorithm itself to avoid false triggering by noise in the signals.

\subsection{Comparison with radiosondes}

Atmospheric sounding by radiosondes has been used in the past for cloud detection validation in polar regions, where clouds are in general characterized by high $\mathrm{RH}_{\text {ice }}$ values (Gettelman et al., 2006; Minnis et al., 2005; Tapakis and Charalambides, 2013). Since our primary goal is the detection of optically thin ice clouds, cloud bases will not always be characterized by significant ice supersaturations, as is the case in the liquid-containing portion of the clouds. Hence, we do not apply radiosonde cloud detection methods such as proposed by Jin et al. (2007). Instead, radiosonde-derived statistical $\mathrm{RH}_{\text {ice }}$ distributions are used to assess the performance of the PT algorithm. The $\mathrm{RH}_{\text {ice }}$ at the level of the detected CBH should in general be high, assuming the actual presence of hydrometeors at this height, while this is not necessarily the case for clear-sky $\mathrm{RH}_{\text {ice }}$. Statistically, clear-sky $\mathrm{RH}_{\text {ice }}$ values should therefore be lower than cloudy $\mathrm{RH}_{\text {ice }}$ values. An example case with ceilometer attenuated backscatter measurements and the radiosonde-derived $\mathrm{RH}_{\text {ice }}$ is shown in Fig. 8. Visual cloud-base determination based on our definition of a cloud indicates a CBH around $500 \mathrm{~m}$. The radiosonde data show that the $\mathrm{RH}_{\text {ice }}$ increases significantly (by $45 \%$ ) at this cloud base, although its absolute value does not indicate ice supersaturation. To assess how the PT algorithm performs, we therefore estimated in a statistical analysis the difference in $\mathrm{RH}_{\text {ice }}$ measurements at the detected cloud base vs. $\mathrm{RH}_{\text {ice }}$ measurements in clear-sky profiles. In order to make this analysis as objective as possible, we first derived a probability distribution for the detected $\mathrm{CBH}$ over all cases. Then, we randomly selected $\mathrm{RH}_{\text {ice }}$ measurements in clear-sky profiles following the same probability distribution in order to set up a sample with an equal amount of clearsky $\mathrm{RH}_{\text {ice }}$ measurements at identical altitudes compared to the $\mathrm{CBH} \mathrm{RH}$ ice measurements. The result is two samples of $\mathrm{RH}_{\text {ice }}$ measurements at the cloud base vs. clear sky, selected 

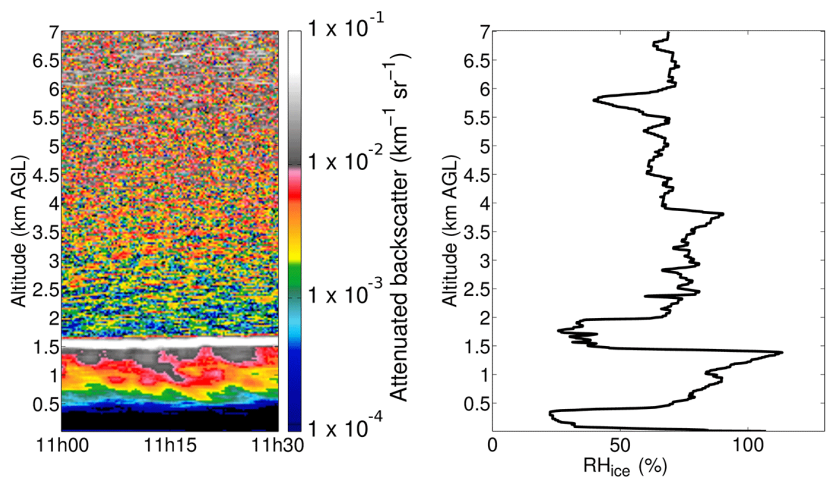

Fig. 8. Comparison between measured attenuated backscatter by ceilometer (left) and $\mathrm{RH}_{\text {ice }}$ by radiosonde (right) at Summit on 5 August 2011.

at the same altitudes with an equal number of observations in each.

The histograms of the two samples (clear sky and cloud base) are plotted in Fig. 9. The green bars indicate occurrences in a $\mathrm{RH}_{\text {ice }}$ interval for the clear-sky sample. Blue bars represent occurrences in a $\mathrm{RH}_{\text {ice }}$ interval for the cloud-base sample. It shows that when a cloud base is detected, the highest occurrences of $\mathrm{RH}_{\text {ice }}$ values at this cloud base are around $110 \%$ with only very few cases lower than $90 \%$. For clear sky, on the other hand, the radiosonde also detects high $\mathrm{RH}_{\text {ice }}$, although more occurrences at very low $\mathrm{RH}_{\text {ice }}$ values are present. The high abundance of large $\mathrm{RH}_{\text {ice }}$ values in clear-sky conditions is related to the high fraction of cloud bases near the surface (Sect. 4.4). Shupe et al. (2013) found that in this region $\mathrm{RH}_{\text {ice }}$ values are typically high due to the frequent occurrence of moisture inversions near the surface. According to Vömel et al. (2007), a possible dry bias in the $\mathrm{RH}$ measurements of the RS92 radiosonde is smallest at low altitudes, suggesting that our conclusions should not be influenced significantly by a possible bias.

We used a one-sided nonparametric two-sample Kolmogorov-Smirnov test to determine if the $\mathrm{RH}_{\text {ice }}$ measurements of cloud bases were significantly higher compared to clear-sky $\mathrm{RH}_{\text {ice }}$ values (Hájek et al., 1967). The test indicates that the cloud-base $\mathrm{RH}_{\text {ice }}$ values are indeed significantly higher than the clear-sky $\mathrm{RH}_{\text {ice }}$ values ( $p$ value $<0.01$ ). If the PT algorithm would often be triggered in clear sky, both distributions would not statistically differ significantly which suggests that the PT algorithm performs well.

\subsection{Optical depth of detected features}

Translating the attenuated backscatter values of the detected hydrometeor layers to optical depths allows a physical interpretation of what the PT algorithm actually detects. Such translation, however, is not straightforward since the optical depth depends strongly on the properties of

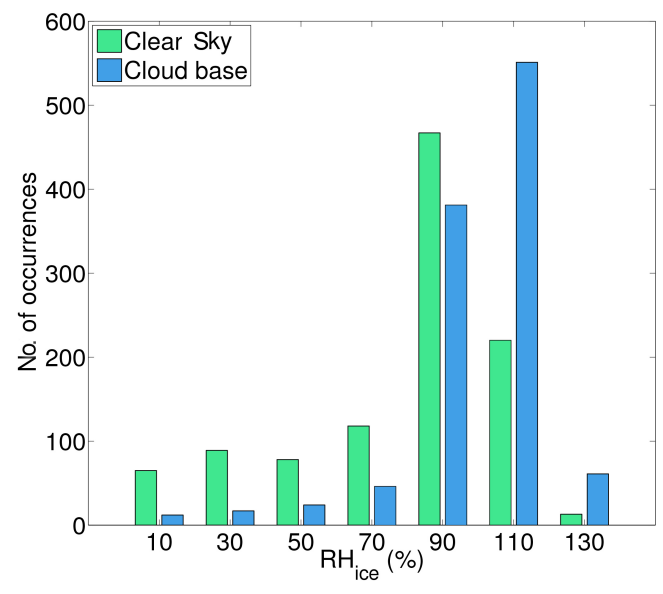

Fig. 9. $\mathrm{RH}_{\text {ice }}$ measurements of radiosondes for clear-sky sample (green bars) and cloud-base sample (blue bars). For clear sky the same height distribution was followed as for cloud base. See text for more information.

the cloud (Tselioudis et al., 1992; King et al., 1998; Kay et al., 2006) and the calculation of optical depth requires the true backscatter coefficients and correction of the observed backscatter for attenuation of the signal is based on knowledge of the extinction profile which is unknown. The true backscatter coefficient was estimated following the procedure described by Platt (1979). This procedure starts with Eq. (2) that describes the relation between observed attenuated backscatter at a height $z\left(\beta_{\text {att }, z}\right)$ and the true backscatter coefficient at this height corrected for attenuation $\left(\beta_{z}\right)$ :

$\beta_{z}=\frac{\beta_{\mathrm{att}, z}}{\exp \left(-2 \times \tau_{z}\right)}$.

In this equation, the exponential term describes the two-way attenuation in the profile between the cloud base $\left(z_{0}\right)$ and height $z$ and $\tau_{z}$ is the optical depth along the path calculated as

$\tau_{z}=\int_{z_{0}}^{z} \sigma \mathrm{d} z=\int_{z_{0}}^{z} S \times \beta_{z} \mathrm{~d} z$,

where $\sigma$ is the extinction coefficient and $S$ is the backscatterto-extinction ratio (lidar ratio). $S$ depends on numerous factors, including size distribution, composition and shape of the particles (Heymsfield and Platt, 1984; Chen et al., 2002). Yorks et al. (2011) found a constant lidar ratio of $S=16 \mathrm{sr}$ for liquid altocumulus clouds and $S=25 \mathrm{sr}$ for ice clouds. As our measurements include a variety of atmospheric conditions from ice to supercooled liquid, we assume an average ratio of $S=20 \mathrm{sr}$ for a rough estimation of the extinction coefficient. After combining Eqs. (2) and (3), the final equation is described by Eq. (4): 


$$
\beta_{z}=\frac{\beta_{\mathrm{att}, z}}{\exp \left(-2 \times S \times \int_{z_{0}}^{z} \beta_{z} \mathrm{~d} z\right)} .
$$

The procedure assumes that at the cloud base $\beta_{z_{0}}=\beta_{\text {att }, z_{0}}$, since attenuation of the signal under the cloud base is negligible. Next, the cloud is divided into a number of layers, corresponding to the range bins of the ceilometer. The integral in Eq. (4) is discretized and the true backscatter coefficients of the range bins are successively calculated until the upper end of the profile is reached. In the procedure, the effects of multiple scattering are not taken into account. In a final step, the optical depth $\tau$ of the detected cloud is cumulatively calculated for the successive range bins, using Eq. (3).

The assumptions for both the lidar ratio $S$ and the derivation of the true backscatter coefficients from observed backscatter make the optical depth calculations prone to a considerable degree of uncertainty. Despite many assumptions simplifying a complex problem, this procedure allows us to make a rough estimation of the optical depth of hydrometeor layers detected by the PT algorithm. We assessed the degree of uncertainty due to the lidar ratio approximation, by varying this ratio $S$ between $16 \mathrm{sr}<S<25 \mathrm{sr}$. The resulting optical depth uncertainty was $25 \%$, which agrees well to similar studies with ceilometer (e.g., Wiegner and Geiß, 2012).

We found at Summit optical depths detected by the PT algorithm as low as $\tau=0.01$ and $32 \%$ of the detected hydrometeor features attenuated the laser beam $(\tau>3$, in accordance with Sassen and Cho, 1992). At PE, the lower limit of optical depths was 0.01 as well, while $21 \%$ of the detections attenuated the laser beam. The drawback of the high sensitivity of the algorithm (detection of features with $\tau=0.01$ ) is that $\mathrm{CBH}$ detection can sometimes be triggered by layers of elevated aerosol contents. This only rarely happens over the Antarctic ice sheet due to its remote location and clean air (e.g., Hov et al., 2007). This is not the case for Greenland, which is much closer to industrialized countries. In the events of elevated aerosol contents, some aerosol layers will inherently be identified falsely as cloud (Shupe et al., 2011), an issue that occurs in other parts of the Arctic as well, for instance in Svalbard (Lampert et al., 2012).

\subsection{Application: cloud properties}

Cloud height is an important property in cloud statistics. We therefore analysed the detected CBH for all cases at Summit and PE to infer some basic cloud statistics: cloud occurrence fraction and $\mathrm{CBH}$ distribution. While the analysis was performed for year-round ceilometer data at Summit (2010-2012), it was constrained to summer observations at PE (December-March, 2010-2013) due to a lack of winter measurements.
The monthly mean cloud occurrence frequency for Summit was derived by applying the PT algorithm in two modes, once in the sensitive mode using the previously determined backscatter threshold of $3 \times 10^{-4} \mathrm{~km}^{-1} \mathrm{sr}^{-1}$ and once using a much higher threshold of $1000 \times 10^{-4} \mathrm{~km}^{-1} \mathrm{sr}^{-1}$. While the former includes the detection of very optically thin hydrometeors $(\tau \sim 0.01)$, the latter is only triggered by clouds that are at least a factor 50 optically thicker $(\tau \sim 0.5)$. A threshold of $1000 \times 10^{-4} \mathrm{~km}^{-1} \mathrm{sr}^{-1}$ has also been used by Hogan et al. (2003) and O'Connor et al. (2004) to identify supercooled liquid layers and they found a minimum optical depth of $\tau=0.7$ for these clouds. Using such high backscatter threshold for the detection of liquid layers makes the PT algorithm less sensitive for increasing noise levels with height, as this high backscatter threshold is not exceeded by the noise level at any height. The PT algorithm in this mode is therefore driven by the backscatter threshold along the entire atmospheric profile. An example profile showing a liquidcontaining cloud is profile $\mathrm{E}$ in Fig. 4, which indicates that such high backscatter signal is indeed strongly exceeding the noise level.

As shown in Fig. 10, there is no apparent seasonal cycle at Summit in mean monthly cloud cover when including the optically thin hydrometeors, with a year-round cloud cover of $72 \%( \pm 10 \%)$. This is in contrast with Wang and Key (2005) who found in central Greenland the lowest annual mean cloud cover in the Arctic with a value of about $45 \%$. Such significant difference is probably due to the high amount of very optically thin ice clouds that are easier to be detected by a ground-based ceilometer using a sensitive algorithm compared to a satellite product from AVHRR used by Wang and Key (2005). Our results show similar trends to Shupe et al. (2013) who found an overall high cloud occurrence fraction at Summit combining multiple ground-based instruments. When the optically thin hydrometeors are deliberately excluded, a seasonal cycle emerges with a summer peak of coverage over $40 \%( \pm 4 \%)$, and almost no detections in winter. This agrees with the seasonal distribution of liquid water at Summit (Shupe et al., 2013). These results are influenced by the SNR noise reduction that was applied prior to the $\mathrm{CBH}$ detection. We assessed the uncertainty in the results due to SNR-threshold choice by varying this threshold from 0.5 to 1.5 . The mean introduced uncertainty was $10 \%$ for the low backscatter threshold and $1.5 \%$ for the high backscatter threshold. These uncertainties are also indicated by the green areas in Fig. 10, showing that the overall trends are fairly insensitive to this SNR-threshold choice.

Figure 11a shows that the CBH for both optically thin (blue curve) and thick (brown curve) hydrometeor layers is close to the surface at Summit, with almost all detections below $500 \mathrm{~m}(87 \%)$. Uncertainties due to SNR-based noise reduction are indicated by the shaded areas. Shupe et al. (2011) found a monthly mean CBH roughly below $1 \mathrm{~km}$ in all months at Summit. The effect of shallow blowing snow layers in the $\mathrm{CBH}$ detection was minimized by excluding the 


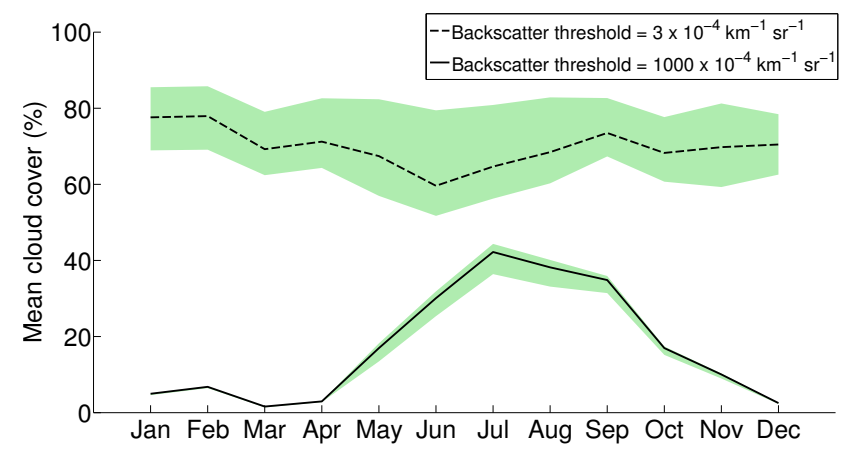

Fig. 10. Monthly mean cloud cover (\%) at Summit (2010-2012) derived with sensitive threshold $\left(3 \times 10^{-4} \mathrm{~km}^{-1} \mathrm{sr}^{-1}\right.$, dashed line) thereby including optically thin hydrometeor layers and higher threshold $\left(1000 \times 10^{-4} \mathrm{~km}^{-1} \mathrm{sr}^{-1}\right.$, solid line) thereby focusing on optically thick hydrometeor layers. The green shaded areas represent uncertainty due to SNR-threshold choice.

first $60 \mathrm{~m}$ of the profile. We found, however, that $90 \%$ of all profiles with detected hydrometeor layers above $60 \mathrm{~m}$ were in fact affected by a significant backscatter signal in the first $60 \mathrm{~m}$. This suggests that at Summit, hydrometeor layers are most frequently present in the first ranges near the surface and can be associated with various phenomena including fog, snowfall and drifting/blowing snow. The $\mathrm{CBH}$ distribution of the remaining $10 \%$ after excluding those profiles affected by hydrometeors in the first $60 \mathrm{~m}$ indicates that some $\mathrm{CBH}$ occurrences are present higher in the profile $(\sim 1.5 \mathrm{~km}$, green curve in Fig. 11a). Cloud bases of the optically thicker hydrometeors are still below $1 \mathrm{~km}$ (red curve).

At PE, we found a mean cloud occurrence fraction in summer of $46 \%( \pm 5 \%)$ for hydrometeor layers with optical depths of at least $\tau \sim 0.01$. When including only optically thicker hydrometeor layers $(\tau \geq 0.5)$, this fraction reduces to $12 \%( \pm 2.5 \%)$. The optically thinnest hydrometeors occur mostly near the surface $(35 \%$ of all detections below $500 \mathrm{~m}$, blue curve in Fig. 11b) and progressively less frequently higher in the profiles. Overall $80 \%$ of the $\mathrm{CBH}$ values of the detected features is below $2 \mathrm{~km}$, of which the 14 March 2011 case in Fig. 7a is a typical example. Using the high backscatter threshold, the resulting $\mathrm{CBH}$ detections that are related to optically thicker clouds probably due to supercooled liquid occur mostly (78\%) between $1 \mathrm{~km}$ and $3 \mathrm{~km}$ (brown curve). Excluding all profiles that are affected by hydrometeors in the first $60 \mathrm{~m}$ reduces the cloud occurrence fraction of all detected clouds to $33 \%$, meaning that $30 \%$ of all profiles containing a hydrometeor layer are affected by near-surface phenomena such as precipitation and blowing/drifting snow. The CBH distribution of the clouds in profiles not affected by these phenomena shows that the optically thin hydrometeor layers are now slightly higher around $500 \mathrm{~m}$ (green curve in Fig. 11), while the optically thicker layers are still concentrated in the 1 to $3 \mathrm{~km}$ region (red curve).

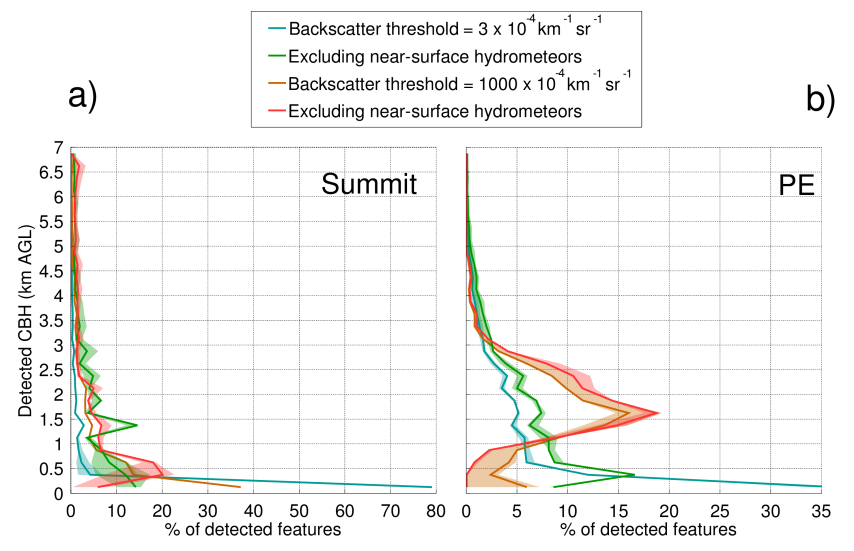

Fig. 11. PT CBH occurrence (\%) for low $\left(3 \times 10^{-4} \mathrm{~km}^{-1} \mathrm{sr}^{-1}\right.$, blue curves) and high $\left(1000 \times 10^{-4} \mathrm{~km}^{-1} \mathrm{sr}^{-1}\right.$, brown curves) thresholds. Also shown is $\mathrm{CBH}$ occurrence after removing profiles affected by hydrometeors in the first $60 \mathrm{~m}$ (green and red curves). Uncertainty of the results due to SNR-threshold choice is indicated by the shaded areas. (a) Analysis for Summit (2010-2012). (b) Analysis for PE, with data limited to summer months (2010-2013).

Overall, most of the $\mathrm{CBH}$ results are situated near the surface for both study sites. These findings have important implications with regard to other remote sensing instruments that are used to study these areas. For example, satellite sensors such as CloudSat carrying an active radar with a blind zone in the lowest ranges due to surface reflection (Marchand et al., 2008) have to take into account that an important part of the hydrometeor layers is situated near the surface.

\section{Advantages and limitations of PT algorithm}

The PT algorithm is designed to be sensitive to optically thin hydrometeor layers. It has been shown in Sect. 4.3 that the algorithm is successful in detecting such layers. However, as discussed in Sect. 3, the increasing noise levels with height in a ceilometer profile cause the sensitivity of the PT algorithm to decrease with height. This inevitably leads to a decreasing amount of detections of the thinnest hydrometeor layers with height. This might imply, for example, that the flat parts of the curves with changing backscatter in Fig. 6 should in reality indicate an increasing amount of detections with decreasing backscatter. Thin ice clouds high in the atmospheric profile can remain undetected by the PT algorithm. This is however a limitation of the ceilometer that would occur with any method.

In an attempt to quantify this limitation, we have calculated the extinction profile corresponding to the PT algorithm's detection sensitivity (Fig. 12). The extinction profile calculated in this way is an indication of the minimum extinction coefficient $\sigma\left(\mathrm{km}^{-1}\right)$ a cloud must have to be detected by the PT algorithm. The extinction coefficient $\sigma$ is found by multiplication of the backscatter coefficient $\beta_{z}$ with 


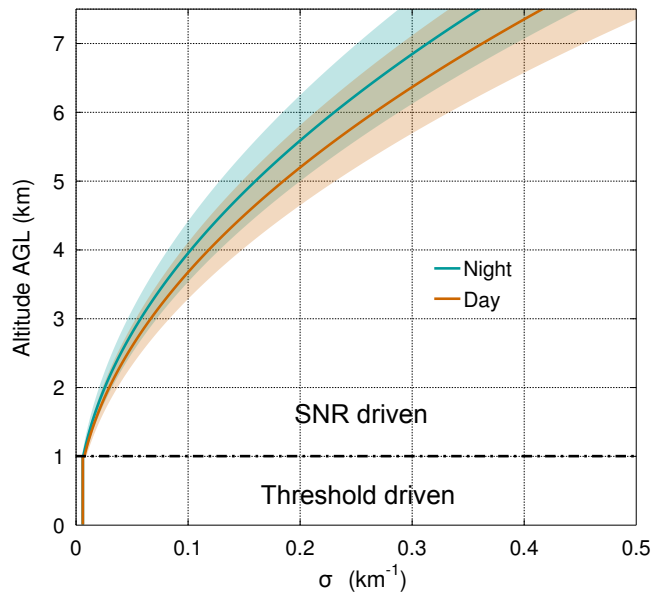

Fig. 12. Extinction profile based on the sensitivity of the PT algorithm for average noise levels during a typical daytime and nighttime case. The shaded areas represent uncertainty due to lidar ratio variation between $16 \mathrm{sr}<S<25 \mathrm{sr}$.

the lidar ratio $S$ (Sect. 4.3). Since the PT algorithm is aiming at the detection of the first hydrometeor layer in a profile, attenuation in the clear polar air below the detection point is negligible, which allows the use of the attenuated backscatter $\beta_{\text {att, } z}$ as an approximation of the true backscatter $\beta_{z}$. The backscatter coefficients used for this extinction profile correspond to the solid orange curve in Fig. 4 that follows the fixed backscatter threshold near the surface and the mean noise level for clear sky higher in the profile. Below the altitude where the PT algorithm uses a fixed backscatter threshold (i.e., $\pm 1 \mathrm{~km}$ ), the sensitivity therefore remains constant (straight parts of the curves in Fig. 12, extinction coefficient of $\sigma \approx 0.006 \mathrm{~km}^{-1}$ ). Above the point where the average noise level exceeds this fixed backscatter threshold, the sensitivity of the PT algorithm becomes dependent on the noise level and hence range. Since the noise level is higher during daytime, when sunlight is scattered into the detector of the ceilometer, the sensitivity of the PT algorithm changes slightly depending on the conditions. We assessed the average noise level with height for typical daytime and night-time profiles at Summit and PE. The extinction profiles corresponding to these noise levels and therefore to the sensitivity of the algorithm are indicated by the brown (daytime) and blue (night-time) curves in Fig. 12. These curves show a slight variation in the algorithm's sensitivity from a certain height onwards depending on the conditions (e.g. $\sigma \approx 0.155 \mathrm{~km}^{-1}$ to $\sigma \approx 0.180 \mathrm{~km}^{-1}$ at $5 \mathrm{~km} \mathrm{AGL}$ ), meaning that during night-time the PT algorithm is slightly more sensitive to optically thin hydrometeor layers compared to daytime. The uncertainty that is introduced by assuming a fixed lidar ratio $S$ is indicated by the shaded areas for which $S$ was varied between $16 \mathrm{sr}<S<25$ sr. This analysis indicates the inevitable decrease of some sensitivity of the PT algorithm that is related to increasing noise levels with height in ceilometer backscatter profiles. However, the overall sensitivity of the PT algorithm remains very high, meaning that this algorithm is suited for the detection of optically thin hydrometeor layers as far as detectable by a ceilometer.

\section{Conclusions}

The importance of occurrence of polar clouds for the energy and mass balance of the ice sheets indicates the need for an improved understanding of the evolution of macro- and microphysical cloud properties. The ceilometer, which is one of the more abundant ground-based instruments in polar regions, can be used to detect cloud bases. The standard algorithms are designed to detect the base heights of liquid clouds as these strongly decrease visibility. However, optically thin ice layers are frequently occurring over the ice sheets. Detection of these ice layers is important in terms of energy and mass balance. In this paper, we propose the new polar threshold algorithm that uses a backscatter threshold to detect optically thin hydrometeors. The optimal attenuated backscatter threshold of $3 \times 10^{-4} \mathrm{~km}^{-1} \mathrm{sr}^{-1}$ was determined by a sensitivity analysis on all available cases for the Princess Elisabeth station in the escarpment zone of East Antarctica and the Summit station in the interior of Greenland. Above the altitude where the average noise level exceeds this fixed value, the detection method becomes SNR driven with a decreasing sensitivity with height. After noise reduction and averaging procedures, the algorithm was shown to identify hydrometeor layers with optical depths as low as 0.01 for clouds near the surface. Comparison with observations by radiosondes at Summit indicated that the observed $\mathrm{RH}_{\text {ice }}$ was significantly higher at the cloud base than in clear-sky conditions, suggesting that the PT algorithm can successfully differentiate between clear-sky and cloudy conditions. Mean cloud cover fraction at Summit is relatively constant year round when the optically thin hydrometeors are included. Optically thicker features (backscatter threshold $1000 \times 10^{-4} \mathrm{~km}^{-1} \mathrm{sr}^{-1}$ ), most probably related to supercooled liquid droplets, show, however, a clear seasonal cycle with a significantly higher cloud cover fraction in summer compared to winter. The greatest part of all cloud detections at Summit was found near the surface. At Princess Elisabeth, the optically thinnest features occur mostly near the surface as well while optically thicker hydrometeor layers occur higher in the profile, mostly between $1 \mathrm{~km}$ and $3 \mathrm{~km}$ above the surface. The high abundance of hydrometeors in the lowest ranges has important implications, for example, when using satellite observations such as CloudSat's active radar which may be insensitive to nearsurface hydrometeors due to surface reflection of the signal. Taking into account inherent limitations of ceilometer observations (such as decreasing sensitivity with height), the PT algorithm is shown to be sensitive to the thinnest hydrometeor layers that are detectable by the instrument. This study therefore indicates that using an adapted algorithm for 
cloud-base height detection, the robust and relatively lowcost ceilometer can be successfully used to extract information from various hydrometeor layers over the ice sheets, including the frequently occurring optically thin ice layers.

Acknowledgements. K. Van Tricht is a research fellow at the Research Foundation Flanders (FWO). S. Lhermitte was supported in the framework of project GO-OA-25 funded by Netherlands Organisation for Scientific Research (NWO) and as postdoctoral researcher for the FWO. I. V. Gorodetskaya was supported via the project HYDRANT funded by the Belgian Science Policy Office under grant number EN/01/4B, in the frame of which PE measurements were performed. J. H. Schween is funded by the Deutsche Forschungsgemeinschaft (DFG) in the transregional collaborative research centre SFB/TR 32. The Summit data were recorded in the frame of the ICECAPS project, which is supported by the US National Science Foundation under grants ARC-0856773, 0904152, and 0856559 as part of the Arctic Observing Network (AON) program, with additional instrumentation provided by the NOAA Earth System Research Laboratory, US Department of Energy ARM Program, and Environment Canada. We are grateful to Christoph Münkel and Reijo Roininen (Vaisala) for continuing support of PE ceilometer and Giovanni Martucci (National University of Ireland) for providing the THT code. We would also like to thank the International Polar Foundation for logistical support at PE and Alexander Mangold (RMI) for help with the HYDRANT instrument maintenance. Finally, we would like to sincerely thank the two anonymous reviewers for their constructive remarks.

Edited by: S. Malinowski

\section{References}

Barnes, J. E., Bronner, S., Beck, R., and Parikh, N. C.: Boundary Layer Scattering Measurements with a ChargeCoupled Device Camera Lidar, Appl. Optics, 42, 2647, doi:10.1364/AO.42.002647, 2003.

Bennartz, R., Shupe, M. D., Turner, D. D., Walden, V. P., Steffen, K., Cox, C. J., Kulie, M. S., Miller, N. B., and Pettersen, C.: July 2012 Greenland melt extent enhanced by low-level liquid clouds, Nature, 496, 83-86, doi:10.1038/nature12002, 2013.

Bernhard, G.: Version 2 data of the National Science Foundation's Ultraviolet Radiation Monitoring Network: South Pole, J. Geophys. Res., 109, D21207, doi:10.1029/2004JD004937, 2004.

Bintanja, R. and Van den Broeke, M. R.: The influence of clouds on the radiation budget of ice and snow surfaces in Antarctica and Greenland in summer, Int. J. Climatol., 16, 12811296, doi:10.1002/(SICI)1097-0088(199611)16:11<1281::AIDJOC83>3.0.CO;2-A, 1996.

Bromwich, D. H., Nicolas, J. P., Hines, K. M., Kay, J. E., Key, E. L., Lazzara, M. A., Lubin, D., McFarquhar, G. M., Gorodetskaya, I. V., Grosvenor, D. P., Lachlan-Cope, T., and van Lipzig, N. P. M.: Tropospheric clouds in Antarctica, Rev. Geophys., 50, RG1004, doi:10.1029/2011RG000363, 2012.

Campbell, J. R., Hlavka, D. L., Welton, E. J., Flynn, C. J., Turner, D. D., Spinhirne, J. D., Scott, V. S., and Hwang, I. H.: Full-Time, Eye-Safe Cloud and Aerosol Lidar Observation at Atmospheric Radiation Measurement Program Sites: Instruments and Data Processing, J. Atmos. Ocean. Tech., 19, 431-442, doi:10.1175/1520-0426(2002)019<0431:FTESCA>2.0.CO;2, 2002.

Chen, W.-N., Chiang, C.-W., and Nee, J.-B.: Lidar Ratio and Depolarization Ratio for Cirrus Clouds, Appl. Optics, 41, 6470-6476, doi:10.1364/AO.41.006470, 2002.

Clothiaux, E. E., Mace, G. G., Ackerman, T. P., Kane, T. J., Spinhirne, J. D., and Scott, V. S.: An Automated Algorithm for Detection of Hydrometeor Returns in Micropulse Lidar Data, J. Atmos. Ocean. Tech., 15, 1035-1042, doi:10.1175/15200426(1998)015<1035:AAAFDO>2.0.CO;2, 1998.

Curry, J. A., Schramm, J. L., Rossow, W. B., and Randall, D.: Overview of Arctic Cloud and Radiation Characteristics, J. Climate, 9, 1731-1764, doi:10.1175/15200442(1996)009<1731:OOACAR>2.0.CO;2, 1996.

Curry, J. A., Hobbs, P. V., King, M. D., Randall, D. A., Minnis, P., Isaac, G. A., Pinto, J. O., Uttal, T., Bucholtz, A., Cripe, D. G., Gerber, H., Fairall, C. W., Garrett, T. J., Hudson, J., Intrieri, J. M., Jakob, C., Jensen, T., Lawson, P., Marcotte, D., Nguyen, L., Pilewskie, P., Rangno, A., Rogers, D. C., Strawbridge, K. B., Valero, F. P. J., Williams, A. G., and Wylie, D.: FIRE Arctic Clouds Experiment, B. Am. Meteorol. Soc., 81, 5-30, doi:10.1175/15200477(2000)081<0005:FACE>2.3.CO;2, 2000.

Dufresne, J.-L. and Bony, S.: An Assessment of the Primary Sources of Spread of Global Warming Estimates from Coupled Atmosphere-Ocean Models, J. Climate, 21, 5135-5144, doi:10.1175/2008JCLI2239.1, 2008.

Ettema, J., van den Broeke, M. R., van Meijgaard, E., van de Berg, W. J., Box, J. E., and Steffen, K.: Climate of the Greenland ice sheet using a high-resolution climate model - Part 1: Evaluation, The Cryosphere, 4, 511-527, doi:10.5194/tc-4-511-2010, 2010.

Flynn, C.: Vaisala ceilometer (model CT25K) handbook, ARM TR-020, available at: http://www.wmo.int/pages/prog/gcos/ documents/gruanmanuals/Z_instruments/vceil_handbook.pdf (last access: 1 March 2014), 2004.

Garrett, T. J. and Zhao, C.: Ground-based remote sensing of thin clouds in the Arctic, Atmos. Meas. Tech., 6, 1227-1243, doi:10.5194/amt-6-1227-2013, 2013.

Gettelman, A., Walden, V. P., Miloshevich, L. M., Roth, W. L., and Halter, B.: Relative humidity over Antarctica from radiosondes, satellites, and a general circulation model, J. Geophys. Res., 111, D09S13, doi:10.1029/2005JD006636, 2006.

Gorodetskaya, I. V., Tremblay, L.-B., Liepert, B., Cane, M. A., and Cullather, R. I.: The Influence of Cloud and Surface Properties on the Arctic Ocean Shortwave Radiation Budget in Coupled Models, J. Climate, 21, 866-882, doi:10.1175/2007JCLI1614.1, 2008.

Gorodetskaya, I. V., Van Lipzig, N. P. M., Van den Broeke, M. R., Mangold, A., Boot, W., and Reijmer, C. H.: Meteorological regimes and accumulation patterns at Utsteinen, Dronning Maud Land, East Antarctica: Analysis of two contrasting years, J. Geophys. Res.-Atmos., 118, 1700-1715, doi:10.1002/jgrd.50177, 2013.

Gorodetskaya, I. V., van Lipzig, N. P. M., Kneifel, S., Van Tricht, K., Maahn, M., Schween, J., and Crewell, S.: Cloud and precipitation properties from ground-based remote sensing in East Antarctica, The Cryosphere Discuss., in preparation, 2014. 
Hájek, J., Šidák, Z., and Sen, P.: Theory of rank tests, Academic press, New York, available at: http://www.library.wisc. edu/selectedtocs/bb596.pdf (last access: 1 March 2014), 1967.

Heese, B., Flentje, H., Althausen, D., Ansmann, A., and Frey, S.: Ceilometer lidar comparison: backscatter coefficient retrieval and signal-to-noise ratio determination, Atmos. Meas. Tech., 3, 1763-1770, doi:10.5194/amt-3-1763-2010, 2010.

Heymsfield, A. J. and Platt, C. M. R.: A Parameterization of the Particle Size Spectrum of Ice Clouds in Terms of the Ambient Temperature and the Ice Water Content, J. Atmos. Sci., 41, 846-855, doi:10.1175/15200469(1984)041<0846:APOTPS>2.0.CO;2, 1984.

Hobbs, P. V. and Rangno, A. L.: Microstructures of low and middlelevel clouds over the Beaufort Sea, Q. J. Roy. Meteorol. Soc., 124, 2035-2071, doi:10.1002/qj.49712455012, 1998.

Hogan, R. J., Illingworth, A. J., O'Connor, E. J., and PoiaresBaptista, J. P. V.: Characteristics of mixed-phase clouds. II: A climatology from ground-based lidar, Q. J. Roy. Meteorol. Soc., 129, 2117-2134, doi:10.1256/qj.01.209, 2003.

Hov, O. Y., Shepson, P., and Wolff, E.: The chemical composition of the polar atmosphere - the IPY contribution, WMO Bulletin, 56, 263-269, 2007.

Intrieri, J. M.: An annual cycle of Arctic surface cloud forcing at SHEBA, J. Geophys. Res., 107, 8039, doi:10.1029/2000JC000439, 2002.

Jin, X., Hanesiak, J., and Barber, D.: Detecting cloud vertical structures from radiosondes and MODIS over Arctic first-year sea ice, Atmos. Res., 83, 64-76, doi:10.1016/j.atmosres.2006.03.003, 2007.

Kay, J. E. and L'Ecuyer, T.: Observational constraints on Arctic Ocean clouds and radiative fluxes during the early 21st century, J. Geophys. Res.-Atmos., 118, 7219-7236, doi:10.1002/jgrd.50489, 2013.

Kay, J. E., Baker, M., and Hegg, D.: Microphysical and dynamical controls on cirrus cloud optical depth distributions, J. Geophys. Res., 111, D24205, doi:10.1029/2005JD006916, 2006.

King, M. D., Tsay, S. C., Platnick, S. E., Wang, M., and Liou, K.-N.: Cloud retrieval algorithms for MODIS: Optical thickness, effective particle radius, and thermodynamic phase, in: Algorithm Theor. Basis Doc. ATBD-MOD-05, NASA Goddard Space Flight Cent., Greenbelt, Md., available at: http://www.modis.whu.edu.cn/chinese/context/info/atmosphere/ atmosphere_optical_mod05.pdf (last access: 1 March 2014), 1998.

Lampert, A., Ström, J., Ritter, C., Neuber, R., Yoon, Y. J., Chae, N. Y., and Shiobara, M.: Inclined lidar observations of boundary layer aerosol particles above the Kongsfjord, Svalbard, Acta Geophys., 60, 1287-1307, doi:10.2478/s11600-011-00674, 2012.

Lubin, D., Chen, B., Bromwich, D. H., Somerville, R. C. J., Lee, W.-H., and Hines, K. M.: The Impact of Antarctic Cloud Radiative Properties on a GCM Climate Simulation, J. Climate, 11, 447-462, doi:10.1175/15200442(1998)011<0447:TIOACR>2.0.CO;2, 1998.

Marchand, R., Mace, G. G., Ackerman, T., and Stephens, G.: Hydrometeor Detection Using Cloudsat - An Earth-Orbiting 94-GHz Cloud Radar, J. Atmos. Ocean. Tech., 25, 519-533, doi:10.1175/2007JTECHA1006.1, 2008.
Martucci, G., Milroy, C., and O'Dowd, C. D.: Detection of Cloud-Base Height Using Jenoptik CHM15K and Vaisala CL31 Ceilometers, J. Atmos. Ocean. Tech., 27, 305-318, doi:10.1175/2009JTECHA1326.1, 2010.

Miloshevich, L. M., Vömel, H., Paukkunen, A., Heymsfield, A. J., and Oltmans, S. J.: Characterization and Correction of Relative Humidity Measurements from Vaisala RS80-A Radiosondes at Cold Temperatures, J. Atmos. Ocean. Tech., 18, 135-156, doi:10.1175/1520-0426(2001)018<0135:CACORH>2.0.CO;2, 2001.

Minnis, P., Yi, Y., Huang, J., and Ayers, K.: Relationships between radiosonde and RUC-2 meteorological conditions and cloud occurrence determined from ARM data, J. Geophys. Res., 110, D23204, doi:10.1029/2005JD006005, 2005.

Münkel, C., Eresmaa, N., Räsänen, J., and Karppinen, A.: Retrieval of mixing height and dust concentration with lidar ceilometer, Bound.-Lay. Meteorol., 124, 117-128, doi:10.1007/s10546-0069103-3, 2006.

Murray, F. W.: On the Computation of Saturation Vapor Pressure, J. Appl. Meteorol., 6, 203-204, doi:10.1175/15200450(1967)006<0203:OTCOSV>2.0.CO;2, 1967.

O'Connor, E. J., Illingworth, A. J., and Hogan, R. J.: A Technique for Autocalibration of Cloud Lidar, J. Atmos. Ocean. Tech., 21, 777-786, doi:10.1175/15200426(2004)021<0777:ATFAOC>2.0.CO;2, 2004.

Pattyn, F., Matsuoka, K., and Berte, J.: Glacio-meteorological conditions in the vicinity of the Belgian Princess Elisabeth Station, Antarctica, Antarct. Sci., 22, 79-85, doi:10.1017/S0954102009990344, 2009.

Pinto, J. O.: Autumnal Mixed-Phase Cloudy Boundary Layers in the Arctic, J. Atmos. Sci., 55, 2016-2038, doi:10.1175/15200469(1998)055<2016:AMPCBL>2.0.CO;2, 1998.

Platt, C. M., Young, S. A., Carswell, A. I., Pal, S. R., McCormick, M. P., Winker, D. M., DelGuasta, M., Stefanutti, L., Eberhard, W. L., Hardesty, M., Flamant, P. H., Valentin, R., Forgan, B., Gimmestad, G. G., Jäger, H., Khmelevtsov, S. S., Kolev, I., Kaprieolev, B., Lu, D.-R., Sassen, K., Shamanaev, V. S., Uchino, O., Mizuno, Y., Wandinger, U., Weitkamp, C., Ansmann, A., and Wooldridge, C.: The Experimental Cloud Lidar Pilot Study (ECLIPS) for Cloud-Radiation Research, B. Am. Meteorol. Soc., 75, 1635-1654, doi:10.1175/15200477(1994)075<1635:TECLPS>2.0.CO;2, 1994.

Platt, C. M. R.: Remote Sounding of High Clouds: I. Calculation of Visible and Infrared Optical Properties from Lidar and Radiometer Measurements, J. Appl. Meteorol., 18, 1130-1143, doi:10.1175/1520-0450(1979)018<1130:RSOHCI>2.0.CO;2, 1979.

Pruppacher, H. and Klett, J.: Microphysics of Clouds and Precipitation, Vol. 18 of Atmospheric and Oceanographic Sciences Library, Springer Netherlands, Dordrecht, doi:10.1007/978-0-30648100-0, 2010.

Rowe, P. M., Miloshevich, L. M., Turner, D. D., and Walden, V. P.: Dry Bias in Vaisala RS90 Radiosonde Humidity Profiles over Antarctica, J. Atmos. Ocean. Tech., 25, 1529-1541, doi:10.1175/2008JTECHA1009.1, 2008.

Roy, G., Vallée, G., and Jean, M.: Lidar-inversion technique based on total integrated backscatter calibrated curves, Appl. Optics, 32, 6754-63, doi:10.1364/AO.32.006754, 1993. 
Sassen, K. and Cho, B. S.: Subvisual-Thin Cirrus Lidar Dataset for Satellite Verification and Climatological Research, J. Appl. Meteorol., 31, 1275-1285, doi:10.1175/15200450(1992)031<1275:STCLDF>2.0.CO;2, 1992.

Sedlar, J., Tjernström, M., Mauritsen, T., Shupe, M. D., Brooks, I. M., Persson, P. O. G., Birch, C. E., Leck, C., Sirevaag, A., and Nicolaus, M.: A transitioning Arctic surface energy budget: the impacts of solar zenith angle, surface albedo and cloud radiative forcing, Clim. Dynam., 37, 1643-1660, doi:10.1007/s00382010-0937-5, 2010.

Shanklin, J., Moore, C., and Colwell, S.: Meteorological observing and climate in the British Antarctic Territory and South Georgia: Part 2, Weather, 64, 171-177, doi:10.1002/wea.398, 2009.

Shupe, M. D. and Intrieri, J. M.: Cloud Radiative Forcing of the Arctic Surface: The Influence of Cloud Properties, Surface Albedo, and Solar Zenith Angle, J. Climate, 17, 616-628, doi:10.1175/1520-0442(2004)017<0616:CRFOTA>2.0.CO;2, 2004.

Shupe, M. D., Walden, V. P., Eloranta, E., Uttal, T., Campbell, J. R., Starkweather, S. M., and Shiobara, M.: Clouds at Arctic Atmospheric Observatories. Part I: Occurrence and Macrophysical Properties, J. Appl. Meteorol. Clim., 50, 626-644, doi:10.1175/2010JAMC2467.1, 2011.

Shupe, M. D., Turner, D. D., Walden, V. P., Bennartz, R., Cadeddu, M. P., Castellani, B. B., Cox, C. J., Hudak, D. R., Kulie, M. S., Miller, N. B., Neely, R. R., Neff, W. D., and Rowe, P. M.: High and Dry: New Observations of Tropospheric and Cloud Properties above the Greenland Ice Sheet, B. Am. Meteorol. Soc., 94, 169-186, doi:10.1175/BAMS-D-11-00249.1, 2013.

Stachlewska, I. S., Piadłowski, M., Migacz, S., Szkop, A., Zielińska, A. J., and Swaczyna, P. L.: Ceilometer observations of the boundary layer over Warsaw, Poland, Acta Geophys., 60, 1386-1412, doi:10.2478/s11600-012-0054-4, 2012.

Sun, Z. and Shine, K. P.: Parameterization of Ice Cloud Radiative Properties and Its Application to the Potential Climatic Importance of Mixed-Phase Clouds, J. Climate, 8, 1874-1888, doi:10.1175/1520-0442(1995)008<1874:POICRP>2.0.CO;2, 1995.

Suortti, T. M., Kivi, R., Kats, A., Yushkov, V., Kämpfer, N., Leiterer, U., Miloshevich, L. M., Neuber, R., Paukkunen, A., Ruppert, P., and Vömel, H.: Tropospheric Comparisons of Vaisala Radiosondes and Balloon-Borne Frost-Point and Lyman- $\alpha$ Hygrometers during the LAUTLOS-WAVVAP Experiment, J. Atmos. Ocean. Tech., 25, 149-166, doi:10.1175/2007JTECHA887.1, 2008.

Tapakis, R. and Charalambides, A.: Equipment and methodologies for cloud detection and classification: A review, Sol. Energy, 95, 392-430, doi:10.1016/j.solener.2012.11.015, 2013.
Tselioudis, G., Rossow, W. B., and Rind, D.: Global Patterns of Cloud Optical Thickness Variation with Temperature, J. Climate, 5, 1484-1495, doi:10.1175/15200442(1992)005<1484:GPOCOT>2.0.CO;2, 1992.

Uttal, T., Curry, J. A., Mcphee, M. G., Perovich, D. K., Moritz, R. E., Maslanik, J. A., Guest, P. S., Stern, H. L., Moore, J. A., Turenne, R., Heiberg, A., Serreze, M. C., Wylie, D. P., Persson, O. G., Paulson, C. A., Halle, C., Morison, J. H., Wheeler, P. A., Makshtas, A., Welch, H., Shupe, M. D., Intrieri, J. M., Stamnes, K., Lindsey, R. W., Pinkel, R., Pegau, W. S., Stanton, T. P., and Grenfeld, T. C.: Surface Heat Budget of the Arctic Ocean, B. Am. Meteorol. Soc., 83, 255-275, doi:10.1175/15200477(2002)083<0255:SHBOTA>2.3.CO;2, 2002.

Verlinde, J., Harrington, J. Y., Yannuzzi, V. T., Avramov, A., Greenberg, S., Richardson, S. J., Bahrmann, C. P., McFarquhar, G. M., Zhang, G., Johnson, N., Poellot, M. R., Mather, J. H., Turner, D. D., Eloranta, E. W., Tobin, D. C., Holz, R., Zak, B. D., Ivey, M. D., Prenni, A. J., DeMott, P. J., Daniel, J. S., Kok, G. L., Sassen, K., Spangenberg, D., Minnis, P., Tooman, T. P., Shupe, M., Heymsfield, A. J., and Schofield, R.: The Mixed-Phase Arctic Cloud Experiment, B. Am. Meteorol. Soc., 88, 205-221, doi:10.1175/BAMS-88-2-205, 2007.

Vömel, H., Selkirk, H., Miloshevich, L., Valverde-Canossa, J., Valdés, J., Kyrö, E., Kivi, R., Stolz, W., Peng, G., and Diaz, J. A.: Radiation Dry Bias of the Vaisala RS92 Humidity Sensor, J. Atmos. Ocean. Tech., 24, 953-963, doi:10.1175/JTECH2019.1, 2007.

Wang, J., Zhang, L., Dai, A., Immler, F., Sommer, M., and Vömel, H.: Radiation Dry Bias Correction of Vaisala RS92 Humidity Data and Its Impacts on Historical Radiosonde Data, J. Atmos. Ocean. Tech., 30, 197-214, doi:10.1175/JTECH-D-12-00113.1, 2013.

Wang, X. and Key, J. R.: Arctic Surface, Cloud, and Radiation Properties Based on the AVHRR Polar Pathfinder Dataset. Part I: Spatial and Temporal Characteristics, J. Climate, 18, 2558-2574, doi:10.1175/JCLI3438.1, 2005.

Wiegner, M. and Geiß, A.: Aerosol profiling with the Jenoptik ceilometer CHM15kx, Atmos. Meas. Tech., 5, 1953-1964, doi:10.5194/amt-5-1953-2012, 2012.

Yorks, J. E., Hlavka, D. L., Hart, W. D., and McGill, M. J.: Statistics of Cloud Optical Properties from Airborne Lidar Measurements, J. Atmos. Ocean. Tech., 28, 869-883, doi:10.1175/2011JTECHA1507.1, 2011. 